\title{
The temperature responses of soil respiration in deserts: a seven desert synthesis
}

\author{
Jessica M. Cable • Kiona Ogle • Richard W. Lucas • Travis E. Huxman • \\ Michael E. Loik - Stanley D. Smith • David T. Tissue • Brent E. Ewers • \\ Elise Pendall $\cdot$ Jeffrey M. Welker $\cdot$ Therese N. Charlet $\cdot$ Meagan Cleary \\ Alden Griffith - Robert S. Nowak • Matthew Rogers • Heidi Steltzer • \\ Patrick F. Sullivan • Natasja C. van Gestel
}

Received: 30 September 2009/Accepted: 1 April 2010/Published online: 23 June 2010

(C) The Author(s) 2010. This article is published with open access at Springerlink.com

\begin{abstract}
The temperature response of soil respiration in deserts is not well quantified. We evaluated the response of respiration to temperatures spanning $67^{\circ} \mathrm{C}$ from seven deserts across North America and Greenland. Deserts have similar respiration rates in dry soil at $20^{\circ} \mathrm{C}$, and as expected, respiration rates are greater under wet conditions, rivaling rates observed for more mesic systems. However, deserts differ in their respiration rates under wet soil at $20^{\circ} \mathrm{C}$ and in the strength of the effect of current and antecedent
\end{abstract}

Electronic supplementary material The online version of this article (doi:10.1007/s10533-010-9448-z) contains supplementary material, which is available to authorized users.

J. M. Cable ( $\square)$

International Arctic Research Center, University of Alaska Fairbanks, Fairbanks, AK 99775, USA

e-mail: jcable@iarc.uaf.edu; jmcable@alaska.edu

K. Ogle · B. E. Ewers · E. Pendall · M. Cleary Department of Botany and Program in Ecology, University of Wyoming, Laramie, WY 82071, USA

K. Ogle

Department of Statistics, University of Wyoming,

Laramie, WY 82071, USA

R. W. Lucas

Department of Forest Ecology and Management, Swedish

University of Agricultural Sciences, Umeå, Sweden

T. E. Huxman

Ecology and Evolutionary Biology Department,

University of Arizona, Tucson, AZ 85721, USA soil moisture on the sensitivity and magnitude of respiration. Respiration increases with temperature below $30^{\circ} \mathrm{C}$ but declines for temperatures exceeding $35^{\circ} \mathrm{C}$. Hot deserts have lower temperature sensitivity than cold deserts, and insensitive or negative temperature sensitivities were predicted under certain moisture conditions that differed among deserts. These results have implications for large-scale modeling efforts because we highlight the unique behavior of desert soil respiration relative to other systems. These behaviors include variable temperature responses and the importance of antecedent moisture conditions for soil respiration.

\author{
T. E. Huxman \\ B2 Earthscience, University of Arizona, Tucson, \\ AZ 85721, USA \\ M. E. Loik \\ Department of Environmental Studies, University \\ of California, Santa Cruz, CA 95064, USA \\ S. D. Smith · T. N. Charlet \\ School of Life Sciences, University of Nevada, \\ Las Vegas, NV 89154, USA \\ D. T. Tissue - N. C. van Gestel \\ Department of Biology, Texas Tech University, \\ Lubbock, TX 79409, USA \\ D. T. Tissue \\ Center for Plants and the Environment, University \\ of Western Sydney, Richmond, NSW 2753, Australia
}


Keywords Hierarchical Bayesian ·

Soil carbon cycling $\cdot Q_{10}$

\section{Introduction}

Deserts remain one of the most under-represented ecosystems in soil respiration syntheses (Lloyd and Taylor 1994; Raich and Potter 1995; Chen and Tian 2005) due to their low productivity, low soil respiration rates, and limited available data (Raich and Potter 1995). However, deserts are important to include in large-scale models because drylands cover a quarter of the earth's land surface (Reynolds 2001), are expanding in area (Dregne 1983), and are rapidly changing. For example, in addition to tremendous human population growth (Geist and Lambin 2004), deserts are experiencing wide-spread woody plant expansion, which has been associated with increases in productivity (Hibbard et al. 2003), soil fertility (McCulley et al. 2004), deep root biomass (Connin et al. 1997), and soil respiration rates (McCulley et al. 2004). Further, climate change is predicted to increase precipitation variability and potentially exacerbate aridity in some desert systems (Christensen et al. 2007; Seager et al. 2007). Such alterations of the hydrological cycle could significantly impact desert ecosystems given that water is the primary driver of biological activity in deserts (e.g., Noy-Meir

J. M. Cable · J. M. Welker · M. Rogers · P. F. Sullivan Environment and Natural Resources Institute, University of Alaska Anchorage, Anchorage, AK 99508, USA

A. Griffith

Wellesley College Botanic Gardens, Wellesley, MA 02482, USA

R. S. Nowak

Department of Natural Resources and Environmental

Science, University of Nevada, Reno, NV 89557, USA

\section{H. Steltzer}

Natural Resource Ecology Laboratory, Colorado State University, Ft. Collins, CO 80523, USA

\section{H. Steltzer}

Department of Biology, Fort Lewis College, Durango, CO 81301, USA

J. M. Welker · M. Rogers · P. F. Sullivan

Biological Sciences Department, University of Alaska Anchorage, Anchorage, AK 99501, USA
1973). Thus, the combined effects of changes in climate, land use, vegetation cover, and desertification make it critical to better understand and quantify desert ecological processes.

Carbon cycling in deserts may be particularly vulnerable to such global climate and land use changes. A critical component of the carbon cycle is the flux of carbon $\left(\mathrm{CO}_{2}\right)$ from the soil to the atmosphere, which we refer to as soil respiration. Soil respiration is an important soil process that may be used as a metric for quantifying desert ecological processes because it is highly responsive to environmental drivers (Xu et al. 2004) and integrates other processes (e.g., microbial decomposition, root activity) that occur at multiple scales (Cardon et al. 2001). Yet, the incorporation of deserts in large-scale syntheses is precluded by lack of data, limited understanding of how desert soil respiration responds to temperature and moisture, and limited understanding of how deserts may differ in their responses. Addressing this knowledge gap is a primary goal of this study.

In general, the temperature sensitivity of soil respiration (e.g., the degree to which soil respiration increases or decreases in response to increasing temperature) is reduced by low substrate availability (Gershenson et al. 2009), low soil moisture (Conant et al. 2004) and high soil temperatures (Chen and Tian 2005; Davidson et al. 2006). The magnitude of soil respiration declines at the extreme ends of the soil moisture and temperature spectra (e.g., Rustad et al. 2001; Davidson et al. 2006), is strongly controlled by soil carbon and substrate content, and belowground biomass (microbial and root) (Schimel et al. 1994). Low soil moisture, low carbon and substrate content, high temperatures, and low biomass characterize the average conditions found in many deserts (Jackson et al. 1996), but deserts are unique because these factors can have high spatial and/or temporal variability. The spatial variability is related to patchy vegetation cover that creates "islands or stripes" of high soil carbon and substrate content within a background of low substrate and carbon content (Schlesinger et al. 1996; Horwath et al. 2008; Czimczik and Welker 2010). Moreover, relatively large amounts of root biomass are found at depth and beneath patches of vegetation (Jackson et al. 1996; Connin et al. 1997). This results in higher respiration rates beneath plants relative to intercanopy spaces (Cable et al. 2008). The temporal 
Table 1 General description of the research sites in each desert

\begin{tabular}{|c|c|c|c|c|c|c|}
\hline Desert & Site location & $\begin{array}{l}\text { Elevation } \\
(\mathrm{m})\end{array}$ & $\begin{array}{l}\operatorname{MAT}\left({ }^{\circ} \mathrm{C}\right) \\
(\min , \max )\end{array}$ & $\begin{array}{l}\text { MAP } \\
(\mathrm{cm})\end{array}$ & $\begin{array}{l}\text { Soil } \\
\text { type }\end{array}$ & SOC $(\%)$ \\
\hline Chihuahuan & $\begin{array}{l}\text { Big Bend National Park } 29^{\circ} 08^{\prime} \mathrm{N}, \\
102^{\circ} 83^{\prime} \mathrm{W}\end{array}$ & 1527 & $18.7(11.3,26.1)$ & 35.6 & SL & $3.7^{\mathrm{a}}$ \\
\hline Great Basin & $\begin{array}{l}\text { Mammoth Lakes, CA } 37^{\circ} 38^{\prime} \mathrm{N} \\
118^{\circ} 58^{\prime} \mathrm{W}\end{array}$ & 2400 & $5.9(-1.9,13.7)$ & 58.6 & SL, VT & $3.8^{\mathrm{a}}$ \\
\hline Mojave & $\begin{array}{l}\text { Nevada Desert FACE Facility, } \\
\text { NV } 36^{\circ} 46^{\prime} \mathrm{N}, 115^{\circ} 57^{\prime} \mathrm{W}\end{array}$ & 955 & $16.1(5.5,26.7)$ & 7.4 & LS & $\begin{array}{l}0.48 \text { (Schaeffer } \\
\text { et al. 2003) }\end{array}$ \\
\hline $\begin{array}{l}\text { Sagebrush } \\
\text { steppe }\end{array}$ & $\begin{array}{l}\text { near Baggs, WY } 41^{\circ} 19^{\prime} \mathrm{N}, \\
107^{\circ} 24^{\prime} \mathrm{W}\end{array}$ & 2276 & $6(-0.9,12.9)$ & 22.8 & SL & $\begin{array}{l}2.3 \text { (Ewers and } \\
\text { Pendall 2008) }\end{array}$ \\
\hline Sonoran & $\begin{array}{l}\text { Santa Rita Exp. Range, } \\
\text { AZ } 31^{\circ} 78^{\prime} \mathrm{N}, 110^{\circ} 88^{\prime} \mathrm{W}\end{array}$ & 1070 & $17.8(11.0,24.7)$ & 56.4 & SL, CL & $0.25^{\mathrm{a}}$ \\
\hline Polar semi-desert & $\begin{array}{l}\text { Pituffik Peninsula, Greenland } 76^{\circ} 33^{\prime} \mathrm{N} \text {, } \\
68^{\circ} 34^{\prime} \mathrm{W}\end{array}$ & 180 & $-11.4(-28,14.5)$ & 12.8 & $\mathrm{~S}$ to $\mathrm{SL}$ & $\begin{array}{l}0.14-1.2 \text { (Sullivan } \\
\text { et al. 2008) }\end{array}$ \\
\hline Polar desert & $\begin{array}{l}\text { Pituffik Peninsula, Greenland } 76^{\circ} 26^{\prime} \mathrm{N} \text {, } \\
68^{\circ} 54^{\prime} \mathrm{W}\end{array}$ & 375 & No data & No data & $\mathrm{S}$ to $\mathrm{SL}$ & No data \\
\hline
\end{tabular}

Climate data for each site was retrieved from the nearest meteorological station reporting to the Western Regional Climate Data Center or the National Climate Data Center: Chihuahuan (Panther Junction, TX), Great Basin (Mammoth Ranger Station, CA), Mojave (Indian Springs, NV), sagebrush steppe (Rawlins airport, WY), Sonoran (Santa Rita Experimental Station, AZ), and Polar semi-desert and desert (Thule Air Force Base and meteorological station at North Mountain, Greenland)

$M A T$ mean annual temperature, MAP mean annual precipitation, $S L$ sandy loam, $L S$ loamy sand, $S$ sand, $C L$ clay loam, $V T$ Volcanic tuff, $S O C$ soil organic carbon measured on the bulk soil, followed by the data source

${ }^{a}$ Unpublished data from van Gestel (Chihuahuan), Loik (Great Basin), and Cable (Sonoran)

variability is also highlighted by long periods of low moisture that are often punctuated by shorter periods of very high soil moisture (Noy-Meir 1973), and large diurnal and seasonal temperature variations are common, including the potential for very cold temperatures (Table 1).

Most deserts are also characterized by highly variable precipitation regimes, where the timing and magnitude of rain events vary inter-annually within and between deserts (Loik et al. 2004). Rainfall variability may become enhanced with climate change, and these changes may include increased frequency of large rain events and more extreme drought periods (Christensen et al. 2007). This may have multifaceted effects on the soil environment, including variable antecedent (or prior) soil moisture conditions that impact soil processes. Recently, antecedent soil moisture conditions have been shown to affect soil carbon processes in deserts and other ecosystems (Fierer and Schimel 2002; Jarvis et al. 2007; Cable et al. 2008), but the effects on the temperature sensitivity and the magnitude of soil respiration are not well understood. Moreover, antecedent soil moisture may differentially impact autotrophic (roots and associated microbes) and heterotrophic (free-living microbes) activity (Fierer and Schimel 2002; Jarvis et al. 2007; Cable et al. 2008), and these components can have different temperature sensitivities (Boone et al. 1998).

The goal of this study is to improve our understanding of soil respiration dynamics in desert systems. To achieve this, we synthesized a large quantity of existing soil respiration data from the four major deserts of North America (Great Basin, Mojave, Sonoran, Chihuahuan) and three additional ecosystems (sagebrush steppe in Wyoming, USA, and a polar desert and semi-desert in Greenland). All seven ecosystems are referred to as "deserts" because they have low annual precipitation (Table 1). Importantly, the inclusion of these seven different sites produced a combined dataset with 3426 observations that spanned soil temperatures ranging from -3 to $63^{\circ} \mathrm{C}$. We conducted a rigorous, Bayesian synthesis of this dataset to evaluate three key questions. First, how does the temperature sensitivity of soil respiration differ between deserts with low and high mean annual temperatures (cold vs. hot deserts)? We expect that soil respiration will be more sensitive to temperature in cold deserts because respiration has been shown to be stimulated by temperature to a 
greater degree under cold conditions (Chen and Tian 2005; Davidson et al. 2006). Second, how does the magnitude of soil respiration rates differ across the seven desert ecosystems? We expect that the magnitude of respiration at a given temperature will be the same across deserts due to the underlying assumption that low soil carbon is common to all deserts. And third, how does current and antecedent soil moisture affect the magnitude and sensitivity of soil respiration across the seven deserts? Given that water is a primary factor controlling biological activity in deserts, we expect that increases in current and/or antecedent water availability will increase respiration rates (e.g., increase the magnitude) and alter the temperature sensitivity of soil respiration.

We conducted a retrospective analysis to address the above questions. We note that the data used in this analysis were collected as part of manipulative experiments that were conducted independent of each other and of this study. We also note that subsets of data were collected using different methods for measuring soil $\mathrm{CO}_{2}$ flux, but a unique aspect of our Bayesian synthesis approach is the ability to analyze the "raw" (or original) data while simultaneously incorporating any methodological effects based on published correction factors associated with the different measurement instruments (Pumpanen et al. 2004; Cable et al. 2008). In particular, our approach allowed us to obtain estimates of the temperature sensitivity and magnitude of soil respiration under a range of soil temperatures and soil water contents. Thus, this study is the first to synthesize desert soil respiration measurements across multiple, diverse desert ecosystems and to quantify the response of respiration to a wide range of temperature, soil moisture, and antecedent conditions. The synthesis methods that we describe are also applicable to other ecosystem types and other ecosystem responses.

\section{Materials and methods}

Field methods and study locations

Here we provide general descriptions of the sites and methods used for field data collection (Tables 1 and 2 , respectively). Volumetric soil water content associated with each measurement date was estimated for the Great Basin, Mojave, Sonoran, and Chihuahuan deserts by inputting the measured soil water content and daily precipitation amounts into the one-dimensional, physically based soil water model, HYDRUS (Simunek and Nimmo 2005). Application of HYDRUS allowed for estimates of volumetric soil water content at the same depths for all the deserts (e.g., 0$15 \mathrm{~cm})$.

Experiments conducted at the Great Basin, Sonoran, and Chihuahuan deserts involved soil moisture manipulations. The water manipulations increased the range of variability in soil moisture, temperature, and soil respiration, which aided in estimating respiration-response parameters associated with moisture effects. The Mojave Desert and sagebrush steppe sites relied only on naturally occurring precipitation and did not manipulate soil water. The polar desert and semi-desert sites received moisture and temperature manipulations (Sullivan et al. 2008; Rogers et al. 2010), but only data from control plots were used in the analysis. It was not the goal of this study to evaluate experimental treatment effects on soil respiration. All the studies used closed-loop, dynamic soil respiration systems (Li-Cor 6400, LiCor 6262, PP Systems), and we accounted for potential artifacts associated with different measurement systems (described later). We note, however, that Pumpanen et al. (2004) did not find statistical differences between these respiration methods. However, we still accounted for potential effects and variability due to measurement method within the hierarchical Bayesian (HB) model by applying method-specific correction factors to the respiration data based on Pumpanen et al. (2004) and Cable et al. (2008). All respiration measurements were made both beneath plant canopies and in intercanopy spaces.

Overview of manipulations and vegetation at each site

The Great Basin Desert study involved snow manipulation experiments that were conducted near Mammoth Lakes, Mono County, California, USA. Snowdepth was manipulated to create increased, decreased, and ambient snow depth plots for each of eight $50+$ year old snow fences; see Loik et al. (2009) for greater detail. The most common species are the shrubs big sagebrush (Artemisia tridentata) and antelope bitterbrush (Purshia tridentata). Other common plant species include trees (Pinus contorta, 
Table 2 Measurement methods used for field data collection

\begin{tabular}{|c|c|c|c|c|c|}
\hline Desert & Soil respiration & Soil moisture & $\begin{array}{l}\text { Soil temperature } \\
\text { (depth; method) }\end{array}$ & $N$ & Measurement dates (year and [day of year]) \\
\hline Chihuahuan & Li-Cor $6400^{\mathrm{a}}$ & $\mathrm{ECH}_{2} \mathrm{O}$ probes $^{\mathrm{b}}$ & $15 \mathrm{~cm} ; \mathrm{HOBO}^{\mathrm{c}}$ & 249 & $\begin{array}{l}2004[257,258] ; 2005[50,51,57,112] ; 2006[48, \\
50]\end{array}$ \\
\hline Great Basin & Li-Cor 6400 & $\mathrm{ECH}_{2} \mathrm{O}$ probes & $5 \mathrm{~cm}$; thermistors ${ }^{\mathrm{d}}$ & 244 & 2003 [183, 192]; 2004 [188-190]; 2006 [281] \\
\hline Mojave & Li-Cor $6262^{\mathrm{a}}$ & $\begin{array}{l}\text { Time Domain } \\
\text { Reflectometry; } \\
\text { Dynamax }^{\mathrm{e}}\end{array}$ & 0-10 cm; HOBO & 1211 & $\begin{array}{l}2003[91-99,105,107-117,127-140,157-162 \\
167-208,217-230,244-272,295-335,344- \\
355] ; 2004[167-182]\end{array}$ \\
\hline Sagebrush & $\begin{array}{l}\text { EGM-3 (2004), } \\
\text { EGM-4 (2005) } \\
\text { with SRC-1 }^{\mathrm{f}}\end{array}$ & $\mathrm{HH} 2^{\mathrm{g}}$ & $\begin{array}{l}0-5 \mathrm{~cm} \text {; HANNA } \\
9053\end{array}$ & 912 & $\begin{array}{l}2004[162-163,189-191,201-202,215-218, \\
222-225,248,270,329] ; 2005[130,137-138, \\
143-146,164-167,178-179,206-209,220-223, \\
234-237,281,316]\end{array}$ \\
\hline Sonoran & $\begin{array}{l}\text { Li-Cor } 6400 \\
\quad(2002) ; \text { Li-Cor } \\
820^{\mathrm{a}}(2003)\end{array}$ & $\begin{array}{l}\text { Time Domain } \\
\text { Reflectometry; } \\
\text { Hydrosense }^{\mathrm{h}}\end{array}$ & $\begin{array}{l}0-10 \mathrm{~cm} ; \text { Li-Cor } \\
\text { temperature probe; } \\
\text { digital thermometer }\end{array}$ & 495 & $\begin{array}{l}2002[157,161,164,168,176,229,230,232,236] \\
2003[159,161,163,167,175,228,230,232, \\
236,244]\end{array}$ \\
\hline $\begin{array}{l}\text { Polar semi- } \\
\text { desert }\end{array}$ & Li-Cor 6400 & Hydrosense & $\begin{array}{l}5 \mathrm{~cm} \text {; digital } \\
\text { thermometer }\end{array}$ & 293 & $\begin{array}{l}2005[164,172,178,205,210,216,222] ; 2006 \\
\quad[170,187,213,227]\end{array}$ \\
\hline Polar desert & Li-Cor 6400 & Hydrosense & $\begin{array}{l}5 \mathrm{~cm} \text {; digital } \\
\text { thermometer }\end{array}$ & 22 & $2004[206,221] ; 2006[214,232]$ \\
\hline
\end{tabular}

$N$ number of data points used in analyses

${ }^{\text {a }}$ Li-Cor Inc, Lincoln, NE

b Dielectric Aquameter $\mathrm{ECH}_{2} \mathrm{O}$-Decagon Devices, Inc, Pullman, WA

c $\mathrm{HOBO}$-Computer Corporation, Bourne, Massachusetts

d Decagon Devices, Inc, Pullman, WA

e Dynamax Inc, Houston, TX

${ }^{f}$ PP Systems, Amesbury, MA

g HH2-Delta-T Devices, Cambridge, UK

${ }^{\text {h }}$ Campbell Scientific, Logan, UT

Pinus jeffreyi), grasses (Achnatherum thurberianum, Elymus elymoides), and forbs (Eriogonum spergulinum, Lupinus lepidus). Soil respiration was measured manually at midmorning in May or June on ambientdepth plots, about two weeks following the end of snowmelt and again in July when soil surface layers $(>25 \mathrm{~cm}$ ) had dried (Table 2).

The Mojave Desert study was conducted at the Nevada Desert FACE Facility (NDFF) and is part of a larger study that is evaluating the effects of elevated $\mathrm{CO}_{2}$ on this ecosystem. The NDFF is characterized by calcareous loamy-sand soils dominated by sparse $(<20 \%$ cover) creosote bush (Larrea tridentata) and white bursage (Ambrosia dumosa) scrub; see Jordan et al. (1999) for details on the experiment and the site. Only ambient $\mathrm{CO}_{2}$ plots were used in this analysis. Three sets of custom-made $(425 \times 94 \times 60 \mathrm{~mm}, 11$ volume) soil respiration cuvettes were installed on fitted base plates in the interspaces between shrub canopies and under shrub canopies. Soil respiration was measured continuously, providing measurements under a wide range of soil water and temperature conditions. To best match collection times at other research sites, we used hourly averages for $9 \mathrm{am}$, $12 \mathrm{pm}$, and $3 \mathrm{pm}$ for Larrea and interspace control plots (those that did not receive the high $\mathrm{CO}_{2}$ treatment).

The Sonoran Desert study was conducted on the Santa Rita Experimental Range near Tucson, Arizona. Replicated rain-exclusion shelters were established at two sites that differed in soil texture. Experimental plots within each shelter were planted with monospecific stands of the native perennial grass, tanglehead (Heteropogon contortus), a nonnative perennial grass, Lehmann lovegrass (Eragrostis lehmanniana), or left bare. Manual respiration measurements were made around single, target precipitation events on plots receiving summer rainfall 
treatments $(50 \%$ above or $50 \%$ below average summer precipitation); see English et al. (2005) for a description of the rain-exclusion shelters and rainfall treatments and Cable et al. (2008) for soil respiration methodology.

The Chihuahuan Desert study was conducted in a sotol grassland ecosystem in the Pine Canyon Watershed in Big Bend National Park. A total of 48 plots were established: 36 plots $(1 \times 0.5 \mathrm{~m})$ contained one individual of sotol (Dasylirion leiophyllum), prickly pear (Opuntia phaeacantha), or sideoats grama (Bouteloua curtipendula), and 12 community plots $(3 \times 3 \mathrm{~m})$ contained all three species. Precipitation manipulations were initiated on the plots in January 2002, which altered the amount of winter and summer rainfall. Soil respiration measurements were made manually on plots that contained only Dasylirion and on all the community plots (Table 2); see Patrick et al. (2007) for details on the study and measurements.

The sagebrush steppe study was conducted in south-central Wyoming. In 2005, a mountain big sagebrush (A. tridentata) fire recovery sequence was established (Cleary et al. 2008), containing sites at four recovery stages: 2, 6, 20 and 39 years since fire (ysf). Plant communities were dominated by the graminoids western wheatgrass (Pascopyrum smithii) and needle and thread (Hesperostipa comata), and forbs including silvery lupine (Lupinus argenteus) until 6 ysf, after which they became dominated by Artemisia (Ewers and Pendall 2008). Soil respiration was measured manually over diurnal cycles (5 times per 24-h cycle) at each of the four sites on five replicate, permanently installed soil collars, and on adjacent soil without soil collars. Only the daytime data were used in this analysis.

The polar semi-desert study involves a multi-level warming by irrigation experiment that was established in June 2003. The plant community, experiment and microclimates of the treatment plots are described by Sullivan et al. (2008) but are not described here because only data from control plots were used in this analysis. At the ecosystem-scale, vascular plants and bare soil/cryptogamic crust each cover $\sim 50 \%$ of the ground surface. Study plots were oriented to span the transition between vascular plants and bare soil/ cryptogamic crust such that each comprised $\sim 50 \%$ of the plot. Manual measurements of mid-day soil respiration were made using permanently installed collars within the vegetated half of the study plots, but in areas that were nearly devoid of aboveground vegetation. When aboveground vegetation was present within the collars, it was carefully removed more than $1 \mathrm{~h}$ before respiration measurements.

The polar desert study involves three small snowfences ( $30 \mathrm{~m}$ in length, $1.5 \mathrm{~m}$ in height) that were established perpendicular to prevailing winds in late August 2003. Study plots were defined and permanent soil collars were installed using the same criteria employed in the polar semi-desert. Manual measurements of mid-day soil respiration were made in control plots and in plots that received experimental increases in winter snow depth. We only used data from control plots in this analysis.

\section{General soil respiration response}

An initial, qualitative examination of the trend in soil respiration with temperature (after accounting for water availability) was conducted to determine if general patterns emerged (Fig. 1). First, the respiration data were divided into three categories based on the relative soil water content at which they occurred (low, medium, and high, Fig. 1a, c). The water content levels were 0 to $33 \%$ (low), 33 to $66 \%$ (medium), and 66 to $100 \%$ (high) of the maximum soil water content measured for each desert (e.g., see SWrel in Eq. 3 below). For each water content category and each desert, the mean respiration rates were calculated for $10^{\circ} \mathrm{C}$ soil temperature categories and plotted against temperature. For each temperature category, we also calculated an overall mean across deserts and plotted the means against temperature (Fig. 1). The overall trend across deserts was plotted for each water content category (Fig. 1d). The purpose of categorizing the respiration data was to distill the 3426 data points into more visible trends. We emphasize that these analyses were conducted as a way to explore potential responses of soil respiration to temperature, after having accounted for water availability. We base our conclusions about the responses of desert soil respiration to temperature and water availability on the more rigorous Bayesian synthesis.

Hierarchical bayesian analysis of soil respiration

The above qualitative examination revealed that the seven deserts characterize different regions of the soil 


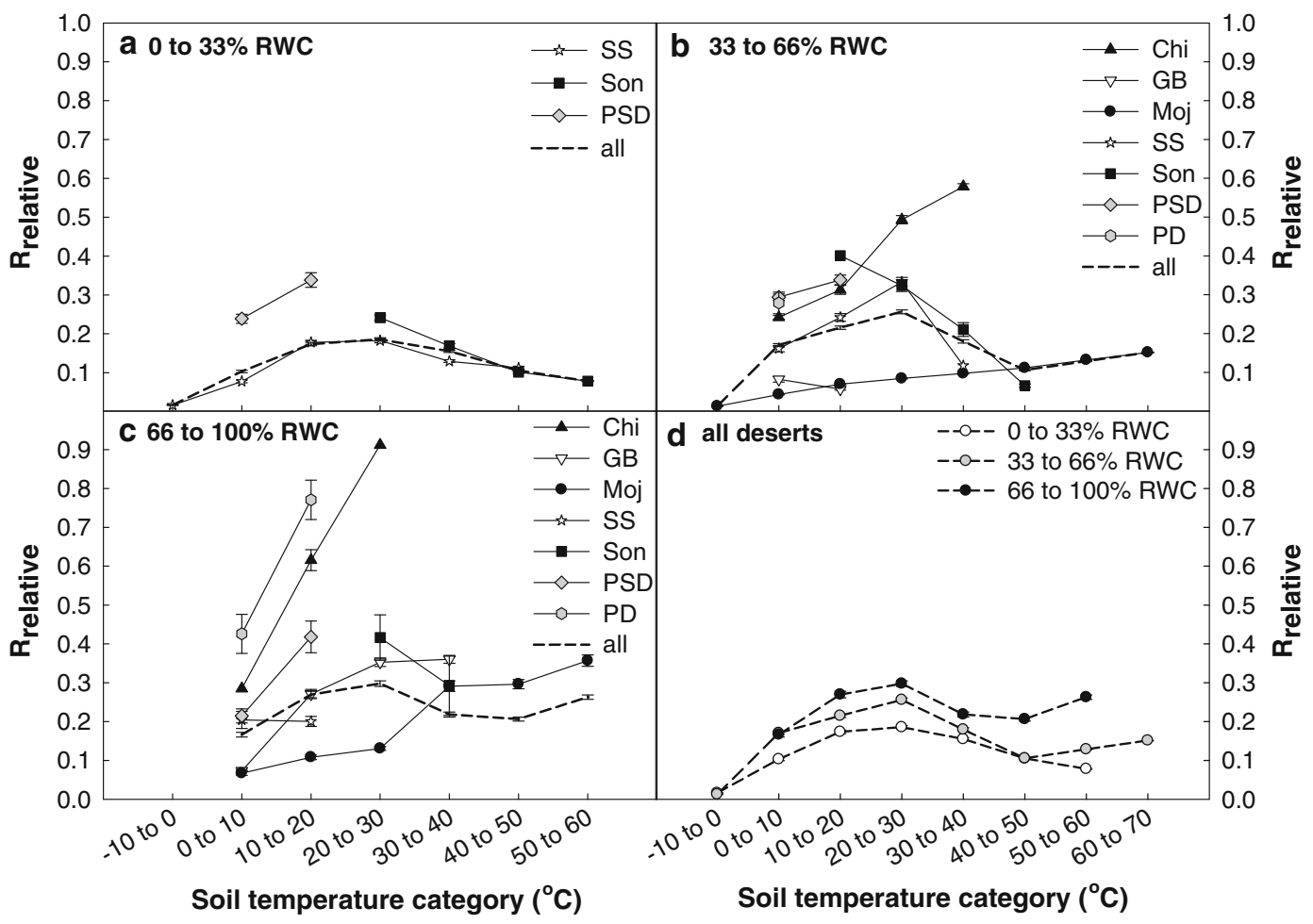

Fig. 1 The respiration rates relative to the maximum for each desert $\left(R_{\text {relative }}\right)$ averaged into $10^{\circ} \mathrm{C}$ soil temperature categories (points are the mean $\pm \mathrm{SE}$ ) and presented in three soil water categories. The categories are based on the relative water contents (RWC), which is the water content relative to maximum for each desert: a 0-33\% RWC, b 33-66\% RWC, and c $66-100 \%$ RWC. Within panels $(\mathbf{a}-\mathbf{c})$, the mean across

respiration-temperature space (Fig. 1). The deserts also differ in their climatic regimes (see Table 1), generating variation in important factors that influence the temperature response of respiration, including current and antecedent soil water conditions (Weltzin et al. 2003; Conant et al. 2004). Thus, these deserts likely differ in the magnitude and temperature sensitivity of soil respiration, and in how moisture and temperature interact to affect respiration. To address our primary questions, we conducted a crossdesert hierarchical Bayesian (HB) analysis (Clark 2005; Ogle and Barber 2008) of the soil respiration data to evaluate the importance of soil water availability, soil temperature, and climate regime.

We first characterized the climatic similarity of the deserts by calculating indices based on differences in mean annual temperature (MAT), mean annual precipitation (MAP), and proximity to one another (Table deserts or "all" is shown, and the deserts are as follows: Chi (Chihuahuan), GB (Great Basin), Moj (Mojave), SS (sagebrush steppe), Son (Sonoran), PSD (Polar semi-desert), and PD (Polar desert). Note that only three deserts (SS, Son, PSD) have data in the $0-33 \%$ RWC category. The "all" lines from (a) to (c) are shown in panel (d) for the three RWC categories

S1 in supplementary material). We used MAT and MAP because we were interested in a general climatic index that could be easily computed from historical climate summaries. Proximity was used because we expect that deserts that are closer to each other may share climatic characteristics not captured by MAP and MAT. For example, the North American Monsoon impacts both the Chihuahuan and Sonoran deserts, and MAT and MAP may not fully capture some of its effects. We also computed an index of antecedent moisture, which is given by the cumulative amount of precipitation received over the 10 days prior to the current measurement day. Prior work suggests that a pulse that occurs 10 days in the past does not affect how soil respiration responds to a pulse that occurs on the current day (Cable unpublished data), so we assumed that 10 days is a wide enough window to capture antecedent effects of rainfall. 
We also explored the effects of current and antecedent soil moisture on soil respiration. The incorporation of the climatic similarity indices within the HB model explicitly allowed for potential correlations between deserts, which also helped to reduce the uncertainty in some desert-specific parameters that were not well-informed by a particular desert's dataset. We analyzed the soil respiration, soil temperature, soil water, antecedent moisture, and climatic similarity data within the HB framework that incorporated a modified version of the Lloyd and Taylor (1994) Arrhenius-type temperature response function that has been applied to soil respiration in a diversity of ecosystems. In preliminary analyses, we applied other temperature functions, including a peaked exponential and a $Q_{10}$ function, but the Lloyd and Taylor (1994) model best fit the data for each desert, and thus we only discuss the HB model with the Lloyd and Taylor respiration function.

The HB model has three components: (1) the data model that describes the likelihood of observed soil respiration; (2) the process model for soil respiration and process or model uncertainty; and (3) the parameter model that specifies prior distributions for all parameters. The three stages are combined to generate posterior distributions of parameters (Clark 2005; Ogle and Barber 2008) that lend insight into the factors controlling soil respiration. The analysis that we conducted is analogous to a classical nonlinear mixed effects model, which would involve the first two stages of the model, but what is unique about the HB approach is the ability to incorporate prior information (e.g., about the measurement methods), the inclusion of a hierarchical parameter model that accounts for climatic similarities among the deserts, and the transparent incorporation of multiple sources of uncertainty. The posterior distributions explicitly quantify uncertainty in all quantities of interest, including model parameters and other derived quantities (e.g., $Q_{10}$, see Eq. 7). The approach also made it straightforward to deal with different methods, whereby we accounted for the measurement uncertainty associated each method.

For the data model, we define the likelihood function for observed soil respiration rates. Based on past work (Cable et al. 2008) and preliminary analyses, we assume that soil respiration $\left(R, \mu \mathrm{mol} \mathrm{m} \mathrm{m}^{-2} \mathrm{~s}^{-1}\right)$ is log-normally distributed, such that for observation $i$ $(i=1, \ldots, 3426)$ : $\ln \left(R_{i}\right) \sim \operatorname{Normal}\left(\mu L R_{i}, \tau\right)$

where $\mu L R_{i}$ is the mean (or expected) log soil respiration rate and $\tau$ is the precision (1/variance) that describes variability associated with observation error or uncertainty.

For the process model, we used a modified version of the Lloyd and Taylor (1994) function to describe $\mu L R_{i}$. We assumed that the base respiration rate $(R b$, the magnitude of soil respiration at $20^{\circ} \mathrm{C}$, $\mu \mathrm{mol} \mathrm{m} \mathrm{m}^{-2} \mathrm{~s}^{-1}$ ) and the temperature sensitivity of respiration $(E o, \mathrm{~K})$ vary with soil water and antecedent precipitation. We also incorporated measurement day random effects $\left(\varepsilon_{\text {day }}\right)$ to describe additional variation introduced by time of year, and we explicitly account for additional variability introduced by different measurement methods used in each desert, where the predicted respiration rate is adjusted for method via a correction factor $(c f)$. Thus, for observation $i$ made on measurement date $t$, and associated with desert $d$ (7 deserts):

$$
\begin{aligned}
\mu L R_{i}= & L R b_{i}+E_{i}\left(\frac{1}{293.15-T_{O}}-\frac{1}{T_{i}-T_{O}}\right) \\
& +\varepsilon_{\text {day }_{t, d}}+\log \left(c f_{i}\right) \\
L R b_{i}= & a_{1 d}+a_{2 d} \cdot \text { SWrel }_{i}+a_{3 d} \cdot \text { lppt }_{i} \\
& +a_{4 d} \cdot \text { lppt }_{i} \cdot \text { SWrel }_{i} \\
\text { Eo }_{i}= & \text { Eob }_{d}+a_{5 d} \cdot \text { SWrel }_{i}+a_{6 d} \cdot \text { lppt }_{i} \\
& +a_{7 d} \cdot \text { lppt }_{i} \cdot \text { SWrel }_{i}
\end{aligned}
$$

where $L R b=\ln (R b)$ is the predicted log base rate, $T_{O}$ $(\mathrm{K})$ is a temperature-related parameter (Lloyd and Taylor 1994), $T$ is measured soil temperature (K) (0$15 \mathrm{~cm}), \mathrm{SWrel}$ is the soil water content relative to the maximum water content reported for each desert ( 0 to $15 \mathrm{~cm})$, and $l p p t=\ln (p p t+1)$, where $p p t$ is antecedent precipitation $(\mathrm{cm})$; we worked with precipitation on the $\log$ scale because precipitation values were approximately log-linearly spaced (i.e., precipitation events were generally small, but a few large events were reported).

The temperature sensitivity of soil respiration $(R)$ describes the degree to which $R$ increases (or decreases) with increasing $T$; that is, the temperature sensitivity is related to the slope of the $R$ versus $T$ response curve. Here, To and Eo are related to the temperature sensitivity but $T o$ is more difficult to interpret; therefore, we treated $T o$ as a scalar parameter common to all deserts, and we refer to 
Eo as the temperature sensitivity. Thus, the $a_{1}$ and Eob parameters represent the desert-specific, predicted base rate and temperature sensitivity, respectively, under very dry conditions (when $\mathrm{SWrel}=0$ and $p p t=0$ ). Note, it is possible to observe biologically relevant soil respiration rates under these extreme dry conditions because deeper $(>15 \mathrm{~cm})$ soil layers may be storing water and supporting biological activity. The other $a$ parameters describe the soil water main effect $\left(a_{2}, a_{5}\right)$, antecedent precipitation effect $\left(a_{3}, a_{6}\right)$, and soil water-by-antecedent precipitation interaction effects $\left(a_{4}, a_{7}\right)$ on $L R b$ and $E o$. These parameters are allowed to vary by desert (hence the $d$ subscript).

Note that the right-hand side of Eq. 2 can be interpreted as the "latent" respiration rate plus a date effect and a correction factor. That is, we apply the correction factor to the latent respiration rate such that the mean (or predicted) value $(\mu L R)$ agrees with the method associated with each observation. We accounted for uncertainty in the correction factors by generating $c f$ values for each observation from a normal distribution with mean $(\mu c f)$ and precision $(\tau c f)$ that were based on the means and $95 \%$ confidence intervals reported in Pumpanen et al. (2004). That is, for observation $i$ associated with desert $d, c f_{i} \sim \operatorname{Normal}\left(\mu c f_{d}, \tau c f_{d}\right)$. We used the following means and precisions: $\mu c f=1.07$ and $\tau c f=348.4$ (std. dev. $=0.04$ ) for the Chihuahuan, Great Basin, Sonoran, polar semi-desert, and polar desert (Li-Cor 6400); $\mu c f=0.910$ and $\tau c f=118.6$ (std. dev. = 0.09) for the Mojave (Li-Cor 6262); and $\mu c f=1.19$ and $\tau c f=61.5$ (std. dev. $=0.13$ ) for the sagebrush steppe (PP Systems). For the Sonoran Desert data, we first adjusted the LI-820 values (measured in 2002) to the LI-6400 values (2003) according to Cable et al. (2008) and subsequently applied the Pumpanen et al. (2004) correction factor associated with the Li-Cor 6400. In this analysis, we simply propagated the uncertainty in the correction factors such that the respiration data did not feedback to adjust the correction factors (this was accomplished via the "cut" function in WinBUGS) (Jackson et al. 2009).

Random effects of measurement day $t$ for each desert $d$ are captured by $\varepsilon_{d a y_{t, d}}$ in Eq. 2 . For desert $d$, we assumed $\varepsilon_{\text {dayt }_{t, d}} \sim \operatorname{Normal}\left(0, \tau_{\varepsilon_{d}}\right)$, where the precision $\left(\tau_{\varepsilon}\right)$ varies between deserts. We implemented sum-to-zero constraints for the date within desert random effects according to the "sweeping" algorithm (Gilks and Roberts 1996).

We modeled the Eob and $a$ parameters in Eq. 3 hierarchically to allow for potential correlations between deserts and to better constrain some of the parameters as some deserts (e.g., Great Basin, polar sites) had relatively small datasets that did not span a wide range of temperature and soil moisture conditions. Thus, for parameter $a_{k}$ and desert $d$, we assumed:

$a_{k, d}=b_{0, k}+b_{1, k} \cdot D_{1, d}+b_{2, k} \cdot D_{2, d}$

where $a_{k}$ represents $E o b$ or any of the $a$ 's in Eq. 3 ( $k$ is the "parameter index"), and $D_{1}$ and $D_{2}$ are "latent indices" that incorporate borrowing of strength between deserts.

The latent desert indices $D_{1}$ and $D_{2}$ (Eq. 4) are vectors of length seven; they are modeled as independent multivariate normal vectors centered on zero, and each vector has its own covariance matrix. That is, the latent, desert-specific indices $D_{k}(k=1$ or 2) are modeled as:

$D_{k} \sim M N_{7}\left(0, \Sigma_{k}\right)$

where $M N_{7}$ indicates a multivariate normal distribution of dimension 7 such that $\Sigma_{k}$ is a $7 \times 7$ covariance matrix. The elements defining the $\Sigma_{k}$ 's are described by the exponential covariance function (Diggle et al. 2002), which is modeled in terms of the climatic similarities between deserts. That is, the correlation structure for $D_{1}$ is based on indices $\left(S_{1 i, j}\right)$ that are determined from the relative differences in MAT and distance between the centers of each research site (or "desert") $i$ and $j\left(\mathrm{Z}_{i, j}\right)$. The correlation structure for $D_{2}$ is based on the indices $\left(S_{2 i, j}\right)$ that are determined from the relative differences in MAP and $\mathrm{Z}_{i, j}$ (Table S1).

The climatic similarity indices $\left(S_{k}\right)$ are used as the "distance" variable in the exponential covariance function for $\Sigma_{k}$. For element $(i, j)$ of $\Sigma_{k}$, which describes the covariance between desert $i$ 's and desert j's latent index:

$\Sigma_{k}(i, j)=\left(\rho_{k}\right)^{S_{k i, j}}$

where $\rho_{k}$ is the correlation coefficient that is estimated. We assigned a mildly informative prior to the two correlation coefficients $\left(\rho_{1}\right.$ and $\left.\rho_{2}\right)$ by assigning each a $\operatorname{Beta}(2.1,1.5)$ prior, which has a 
variance of 0.0528 (std. dev. $=0.2298$ ). In contrast, a more non-informative prior would be a $\operatorname{Beta}(1,1)$, which has a larger variance of 0.0833 (std. dev. = 0.2886). We chose the slightly more informative prior because it reduces the likelihood of obtaining extreme values for $\rho_{k}$ (i.e., $\rho_{k}=0$ or 1 ), which can cause numerical difficulties within the computational framework. Given that the correlation coefficients are removed from the data by several levels in the hierarchical model, the mildly informative prior helped constrain the estimates of these parameters while having little impact on overall model fit.

The final stage is the specification of the priors. We specified non-informative priors for all remaining parameters, including those defining the hierarchical model for the $a$ 's in Eq. 4, with the exception of Eob in Eq. 3 and $T_{O}$ in Eq. 2. Lloyd and Taylor (1994) suggest that $E_{O}$ and $T_{O}$ are relatively conserved across a variety of ecosystem types. Thus, we used somewhat informative normal priors for the "base" $E_{O}$ value (i.e., Eob, Eq. 3) and $T_{O}$ with means given by the Lloyd and Taylor (1994) estimates (308.56 and $227.13 \mathrm{~K}$, respectively) and relatively small precisions of 0.001 and 0.01 (variance $=1000$ and 100), respectively. As required by the model, we restricted To to lie between 0 and $270 \mathrm{~K}(270 \mathrm{~K}$ is less than the lowest soil temperature measured across all deserts). We specified a hierarchical model for the desertspecific standard deviations for the date random effects (the $\sigma_{\varepsilon}=1 / \operatorname{sqrt}\left(\tau_{\varepsilon}\right)$ terms) such that the $\sigma_{\varepsilon}$ 's arise from a folded Student-t distribution with two degrees of freedom and scale parameter $A$ (Gelman 2006); we assigned a diffuse uniform prior to $A$. We also assigned a uniform prior to the observation standard deviation $(\sigma=\sqrt{1 / \tau})$ (Gelman 2006). We assigned diffuse normal priors to the $b_{0, k}, b_{1, k}$ and $b_{2, k}$ coefficients in Eq. 4 (mean $=0$, precision $=0.0001$ or variance $=10000$ ). All distributions are parameterized according to Gelman (2004).

The HB model was implemented in the Bayesian statistical software package WinBUGS (Spiegelhalter et al. 2002). We ran six parallel MCMC (Markov chain Monte Carlo) chains for 11,000 iterations each, and we used the Brooks-Gelman-Rubin (BGR) diagnostic tool to evaluate convergence of the chains to the posterior distribution (Brooks and Gelman 1998; Gelman 2004). We discarded the burn-in samples (first 4,000) and thinned every 5th iteration, yielding an independent sample of about 8400 values for each parameter from the joint posterior distribution (Gelman 2004).

Lastly, we calculated a predicted $Q_{10}$ of respiration, which provides an alternative and commonly reported index of temperature sensitivity, for each desert based on Eq. 2. $Q_{10}$ describes the multiplicative change in soil respiration with a $10^{\circ} \mathrm{C}$ increase in temperature. The $Q_{10}$ of soil respiration for each observation $i$ is given by:

$Q_{10 i}=\exp \left(E o_{i} \cdot\left(\frac{1}{T_{i}-5-T_{O}}-\frac{1}{T_{i}+5-T_{O}}\right)\right)$

For each desert $d$, we computed the average predicted $Q_{10}$ by averaging the $Q_{10 i}$ values over all observations $i$ associated with each desert $d$. To place our study in a broader context, we compare our findings with those from mesic ecosystems. To this end, we extracted $Q_{10}$ and $R b$ estimates from the literature for 28 different sites and we calculated the mean and 2.5th and 97.5th percentiles for $Q_{10}$ values across the sites (Fierer et al. 2006; Peng et al. 2009); we also compare our results to the mean base rate at $20^{\circ} \mathrm{C}$ reported for six different ecosystem types by Lloyd and Taylor (1994). We restricted our comparison to mesic systems, and thus only used data reported for ecosystems with MAP $>500 \mathrm{~mm}$.

\section{Results}

General response of desert soil respiration

The mean antecedent precipitation, soil moisture, soil water, and respiration data for the seven deserts are found in Table 3. Qualitative examination of the data in Fig. 1 shows that, across all deserts, respiration rates peak between 20 and $30^{\circ} \mathrm{C}$ (Fig. 1d), and rates are higher under high soil moisture conditions (Fig. 1a-d). The peak in soil respiration versus temperature occurs around $30^{\circ} \mathrm{C}$, and soil respiration tends to decline at the cold and hot extremes (Fig. 1). This shows that respiration is stimulated by warming for soil temperatures below $30^{\circ} \mathrm{C}$, and it has a positive temperature sensitivity at colder temperatures and a negative sensitivity at warmer temperatures (Fig. 1). The data show a gradual decline in soil respiration at high temperatures $\left(>40^{\circ} \mathrm{C}\right)$ and non- 
Table 3 Mean (minimum, maximum) antecedent precipitation (A-PPT), soil temperature (T), soil water (SW), and soil respiration $(R)$ for the seven deserts

\begin{tabular}{lllll}
\hline Desert & A-PPT $(\mathrm{cm})$ & $T\left({ }^{\circ} \mathrm{C}\right)$ & $\mathrm{SW}(\%)$ & $R\left(\mu \mathrm{mol} \mathrm{m}^{-2} \mathrm{~s}^{-1}\right)$ \\
\hline Chihuahuan & $0.32(0,2.1)$ & $19.7(7.3,36.9)$ & $5.53(4.33,10.4)$ & $1.46(0.32,3.26)$ \\
Great Basin & $0.60(0,1.7)$ & $17.8(4.7,33.9)$ & $2.79(2.15,3.78)$ & $0.97(0.15,3.67)$ \\
Mojave & $0.04(0,0.33)$ & $28.2(-3.1,63.9)$ & $3.66(2.96,6.56)$ & $0.33(0,3.30)$ \\
Sagebrush steppe & $0.59(0,2.84)$ & $19.5(-0.2,54.9)$ & $13.0(0,52.4)$ & $2.45(0,13.4)$ \\
Sonoran & $4.87(0,13.9)$ & $34.5(19,54.9)$ & $7.29(2.26,26.5)$ & $1.96(0.02,10.2)$ \\
Polar semi-desert & $0.96(0,2.21)$ & $9.32(1.4,16.0)$ & $27.4(14,57.3)$ & $1.70(0.40,5.01)$ \\
Polar desert & $1.26(0.61,2.21)$ & $7.22(4.0,13.6)$ & $31.7(18.7,45)$ & $0.90(0.35,2.04)$ \\
\hline
\end{tabular}

zero fluxes are sustained beyond $45^{\circ} \mathrm{C}$ (Fig. 1). The Mojave is the exception to this pattern because soil respiration and temperature are relatively uncoupled across the broad range of temperatures examined here (Fig. 1). Although this type of peaked response is not unusual (Parton et al. 1993), it is intriguing that the seven deserts fall on different parts of the peaked curve. This indicates that some deserts typically exhibit positive temperature sensitivities and others negative sensitivities depending on their climatic regimes or where they occur in the soil temperature space.

\section{Variation in responses of desert soil respiration}

We conducted a hierarchical Bayesian (HB) analysis of the soil respiration data to explore in greater detail the soil respiration response to temperature across the deserts. The HB model fit the respiration data well $\left(R^{2}=0.71 ; N=3426\right)$, but the goodnessof-fit differed between deserts (Fig. S1), where the Chihuahuan had the best fit $\left(R^{2}=0.70\right)$ and the polar desert and semi-desert had the lowest fit $\left(R^{2}=0.33\right)$. Differences in the temporal resolution and amount of data for each desert may partly explain the low $R^{2}$ value (Table 2). Posterior estimates for the respiration parameters in Eqs. 2 and 3 are given in Table 4.

With regard to the temperature sensitivity of soil respiration, the polar ecosystems have the highest average $Q_{10}$ and Eo values, and the Sonoran and Great Basin have the lowest (Fig. 2a). Surprisingly, the Mojave has the third highest temperature sensitivity, surpassed only by the two polar ecosystems (Fig. 2a). Similar to the $Q_{10}$ values, the $E o$ values for the Mojave and polar semi-desert were similar to or higher than the "average" value $(308.6 \mathrm{~K})$ reported by Lloyd and Taylor (1994), but the Eo values for the other deserts were significantly lower than this average value (Table 4). The magnitude of respiration at $20^{\circ} \mathrm{C}(R b)$ was enhanced by high soil water content in all but the Great Basin and Sonoran (Fig. 2b). The $R b$ rates in wet soil (i.e., for SWrel $=1$, which corresponds to the maximum, desert-specific soil water contents reported in the dataset) were comparable for the polar ecosystems, sagebrush steppe, and the Chihuahuan, and lower in the Mojave, Sonoran, and Great Basin. The $R b$ rates in dry soil (i.e., $S W r e l=0$ and $l p p t=0$ ) were highest in the sagebrush steppe and polar ecosystems, intermediate in the Great Basin, Chihuahuan, and Sonoran, and lowest in the Mojave (Fig. 2b).

These differences in the respiration parameters support the body of literature showing that water availability is a critical factor impacting soil respiration dynamics in many of these deserts (Sponseller 2007; Cable et al. 2008; Jin et al. 2009). However, we show that the temporal scale of water availability is critical, such that current soil moisture and antecedent precipitation both influence soil respiration. However, the relative importance of each of these moisture factors differs between deserts and between the respiration parameter of interest (i.e., the magnitude of respiration, $R b$, or the sensitivity to temperature, Eo) (Table 4). For example, high soil moisture $(S W r e l=1)$, regardless of antecedent conditions, reduces the temperature sensitivity (decreased $E o$ and $Q_{10}$ ) in the Sonoran and Great Basin deserts such that respiration is nearly uncorrelated (Sonoran) or more negatively correlated 


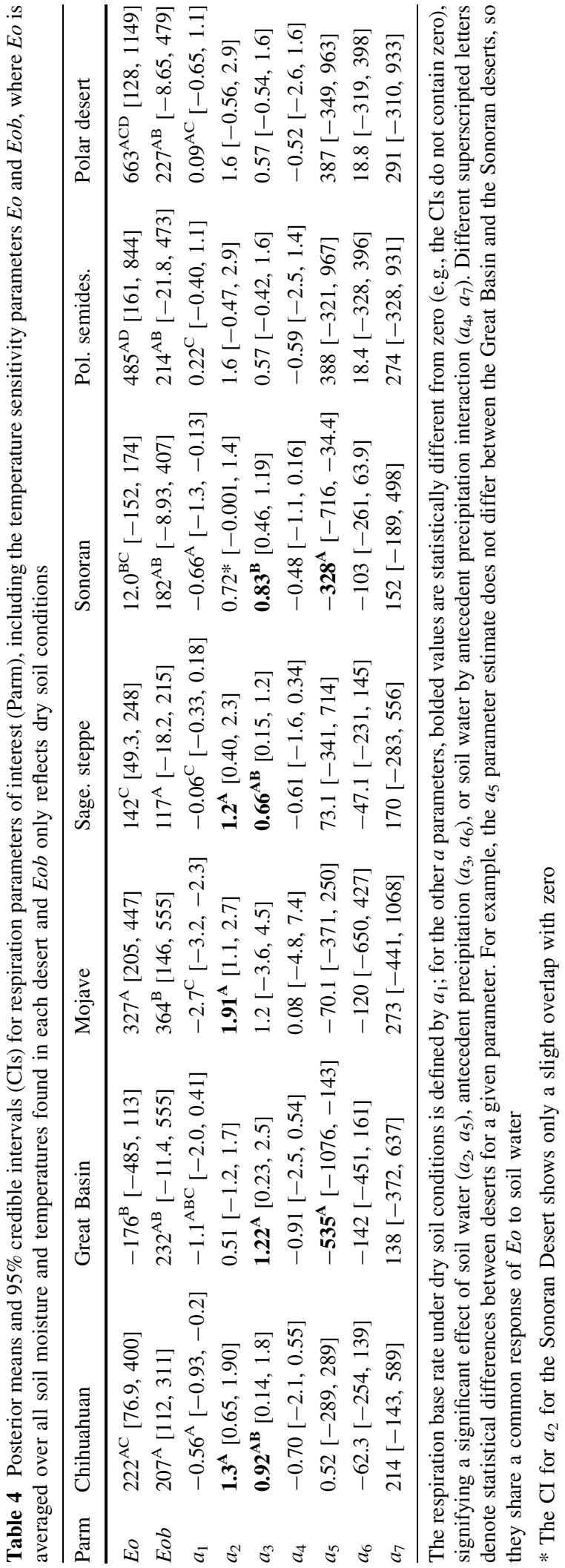

(Great Basin) with soil temperature. Current soil moisture content does not impact temperature sensitivity in the other deserts (see estimates of $a_{5}, a_{6}$, $a_{7}$, Table 4). In the Chihuahuan Desert and sagebrush steppe, high antecedent precipitation (e.g., Table 4) or high soil moisture always results in high respiration rates $(R b)$. Conversely, $R b$ in the Mojave increases with increasing soil water content, but is not coupled to antecedent precipitation. In the Sonoran and Great Basin, high $R b$ is correlated with high antecedent conditions. The soil moisture effect is strongest in the Mojave (largest $a_{2}$ value), and the antecedent effect is strongest in the Great Basin (largest $a_{3}$ value) and weakest in the sagebrush steppe, Sonoran, and Chihuahuan (smallest $a_{3}$ values). Interestingly, either index of water availability did not explain variation in Eo values in the Chihuahuan, Mojave, sagebrush steppe, and polar ecosystems (i.e., $a_{5}, a_{6}, a_{7}$ did not differ from zero, Table 4). Neither short- nor long-term water status affects $R b$ or Eo in the polar ecosystems (Table 4).

Within the HB model, we also obtained estimates of an alternative index of temperature sensitivity $\left(Q_{10}\right)$ for different combinations of current and antecedent soil moisture at average soil temperatures for each desert (Fig. 3). All combinations of soil moisture and antecedent precipitation conditions result in temperature insensitive respiration $\left(Q_{10}=1\right)$ or negative temperature sensitivity $\left(Q_{10}<1\right)$ in the Great Basin and Sonoran deserts (Fig. 3). The posterior means for the $Q_{10}$ values are always greater than one for the other deserts, indicating positive temperature sensitivity. However, statistically significant positive sensitivities are only predicted for low antecedent moisture in the Chihuahuan and Mojave and for a relatively restrictive range of low antecedent and low/ moderate soil moisture in the sagebrush steppe (Fig. 3). The polar ecosystems have positive temperature sensitivity across a wide range of conditions, and they only appear to be insensitive to temperature when soil water content is very low or when both soil water and antecedent precipitation are very high (Fig. 3). Due to high uncertainty (wide credible intervals that contain one) in the $Q_{10}$ values under high antecedent moisture, respiration appears insensitive to temperature in the Chihuahuan, Mojave, and sagebrush steppe under such conditions across a large range of soil moisture contents (Fig. 3). 


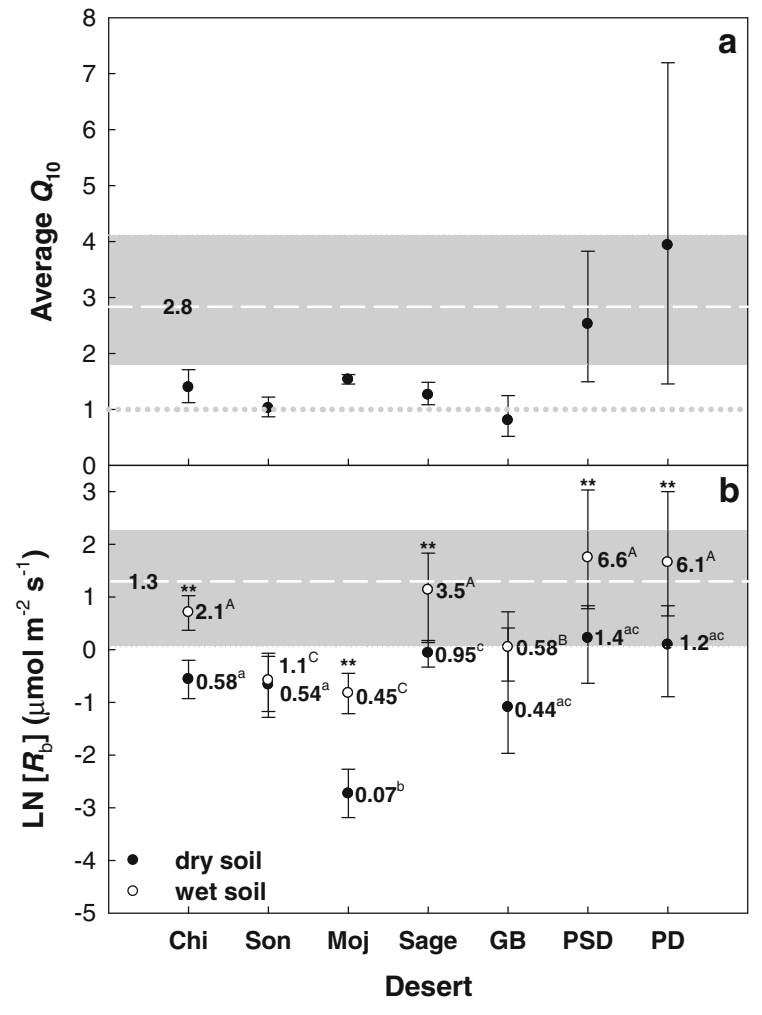

Fig. 2 The posterior means and 95\% credible intervals for: a predicted $Q_{10}$ averaged over all the observed soil moisture and temperature conditions (hence, "Average $Q_{10}$ ") for each desert. The gray dotted line denotes $Q_{10}=1$, where $Q_{10}<1$ indicates negative sensitivity and $Q_{10}>1$ indicates positive sensitivity. b The natural $\log (\mathrm{LN})$ of the base respiration rate $(R b)$ for dry $(S W r e l=0)$ and wet $(S W r e l=1)$ current soil conditions, with low antecedent precipitation in both cases $($ lppt $=0)$. In (a) and (b), the white dashed lines are the mean values extracted from the literature for mesic systems, and the gray shaded region represents the 2.5 th and 97.5 th percentiles or $95 \%$ confidence intervals derived from a $Q_{10}$ values reported in Fierer et al. (2006) and Peng et al. (2009), and b respiration at $20^{\circ} \mathrm{C}$ reported in Lloyd and Taylor (1994). Statistical differences across the deserts within both wet and dry conditions are denoted by superscripted letters next to each point. ** Significant differences between the wet and dry base rates within a desert. The deserts are arranged from left to right as the hottest to coldest: Chihuahuan (Chi), Sonoran (Son), Mojave (Moj), sagebrush steppe (Sage), Great Basin (GB), polar semi-desert (PSD), and polar desert (PD)

\section{Discussion}

This study presents a novel synthesis of soil respiration datasets from seven desert ecosystems spanning a $67^{\circ} \mathrm{C}$ range in soil temperature. Specifically, we synthesized original observations from different studies and explicitly accounted for important sources of uncertainty such as time (date) effects and measurement instrument artifacts. The results from this rigorous analysis lend important insight into the soil respiration behavior of arid and semiarid ecosystems. For example, we found some general properties in the response of respiration across deserts, where the deserts define a common peaked temperature response, respiration rates under dry soil conditions at a common temperature are similar across deserts, and respiration rates are greater with high current soil moisture or moist antecedent conditions. High current moisture conditions refer to the highest soil water content values measured in each desert, which are typically nonsaturating levels. However, we also found important differences across deserts: (1) hot deserts have lower temperature sensitivity than cold deserts; (2) respiration rates under wet soil conditions differ at a common temperature $\left(20^{\circ} \mathrm{C}\right)$; (3) high current soil moisture reduces the temperature sensitivity in the more semiarid deserts (higher MAP); (4) high current or antecedent soil moisture enhances the magnitude of respiration in deserts with moderate MAP; (5) either index of soil moisture does not explain variation in the sensitivity or magnitude in respiration in deserts with low MAP (except the Mojave, where current soil moisture positively affects $R b$ ); and (6) moist antecedent conditions result in temperature insensitivity in all but the polar ecosystems.

The general pattern in respiration rates with temperature was interesting (Fig. 1), and this suggests that some deserts exhibit positive or negative temperature sensitivities depending on where they occur in the overall soil temperature space. Regarding our first primary research question, this synthesis shows that soil respiration is most sensitive to temperature in the cold polar ecosystems and is insensitive to temperature in the hot Sonoran Desert (Fig. 2a and Table 4). However, respiration in the Mojave (hot desert but colder winters than the Sonoran) is very sensitive to temperature, and the Great Basin (cold temperate desert) has negative temperature sensitivity (Fig. 2a and Table 4). The non-polar deserts have lower temperature sensitivities compared to mesic ecosystems, but the polar ecosystems have similar sensitivities (Fig. 2a and Table 4). 


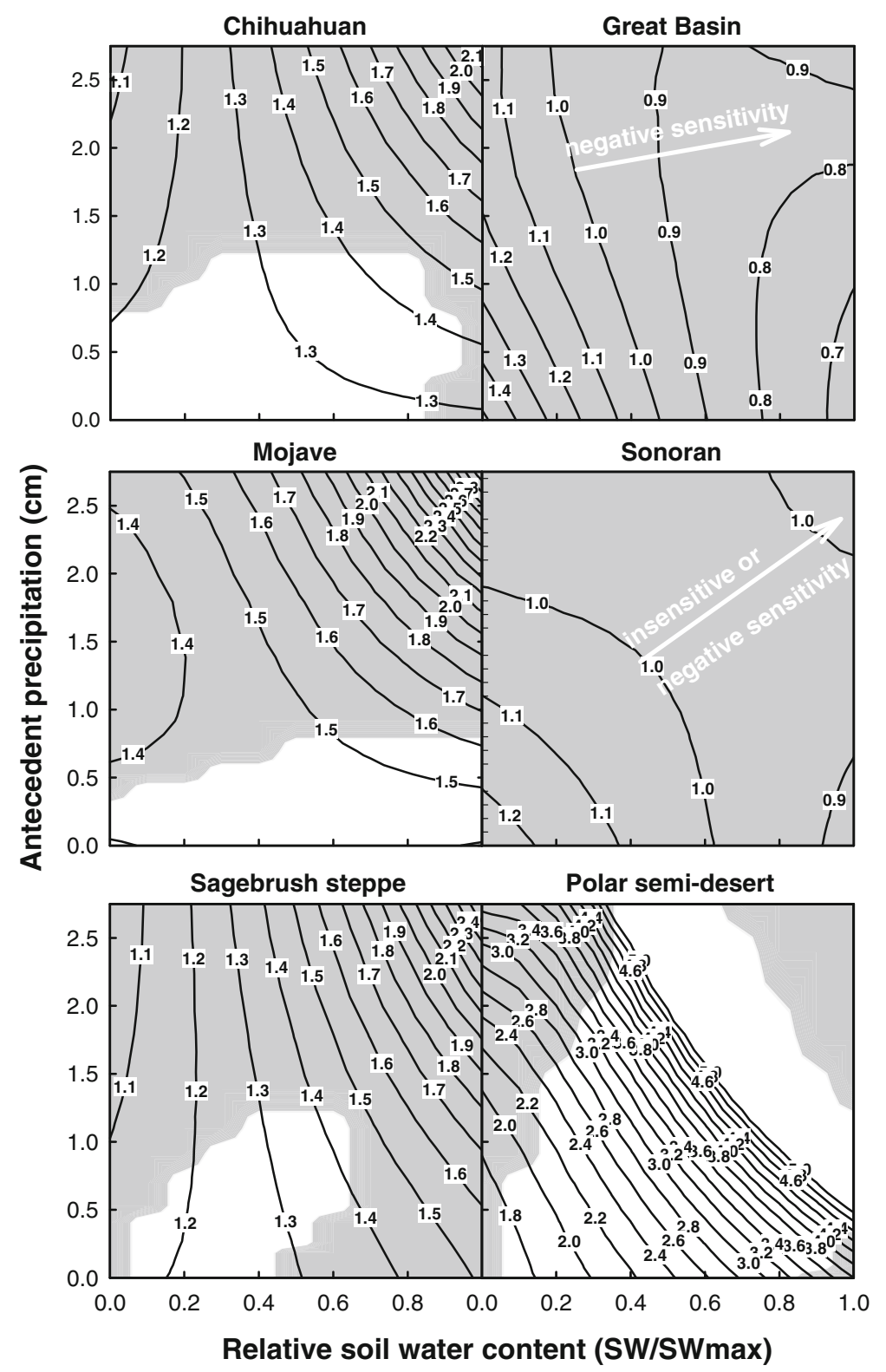

Fig. 3 Estimated $Q_{10}$ values for a range of soil moistures (relative soil water content, $\mathrm{SWrel}$ ) and antecedent precipitation conditions for six of the seven deserts; lppt $=\log ($ antecedent precipitation $[\mathrm{cm}]+1), \mathrm{SW}=$ soil water content $(\%)$, and $\mathrm{SW}_{\max }$ is the maximum SW content observed for each desert $\left(\right.$ SWrel $\left.=\mathrm{SW} / \mathrm{SW}_{\max }\right)$. The $Q_{10}$ values were calculated within the Bayesian MCMC simulations such that uncertainties in the parameters (i.e., To and those associated with Eo, see Eqs. 7 and 3) were propagated through to the $Q_{10}$ calculations. The $Q_{10}$ values were predicted for nominal soil temperatures for each desert: $30^{\circ} \mathrm{C}$ for the Chihuahuan, Mojave, Sonoran, $20^{\circ} \mathrm{C}$ for the Great Basin and sagebrush steppe, and $5^{\circ} \mathrm{C}$ for the polar sites. The predicted $Q_{10}$ values were similar for both polar sites, so only the polar semi-desert is shown. Thus, the contours represent the posterior means for the $Q_{10}$ values; the white regions indicate $Q_{10}$ values that are significantly greater than one (positive temperature sensitivity) such that the $95 \%$ credible interval (CI) contained value greater than one (and one was not in the $\mathrm{CI}$ ); the gray regions indicate negative sensitivities $\left(Q_{10}<1\right.$; the $95 \%$ CI contained values less than one) or $Q_{10}$ values that did not differ from one (i.e., although the posterior mean may be greater than one, the $95 \% \mathrm{CI}$ contained one) 
Temperature sensitivity of respiration

The low temperature sensitivities we observed for many of the deserts could be related to the depth at which soil temperature was measured (e.g., surface soil $\sim 0-15 \mathrm{~cm}$, Table 1). Microbial density tends to be higher near the surface in desert soils (Cable et al. 2009), where nearly $90 \%$ of microbial activity occurs from 0 to $15 \mathrm{~cm}$ (Fierer et al. 2003), and the near-surface microbes tend to be less temperature sensitive than those located deeper in the soil (Fierer and Schimel 2003). Roots can extend into deep soil layers in deserts, but the majority of root biomass and respiration occurs within the top $50 \mathrm{~cm}$ of soil (Pregitzer et al. 1998; Schenk and Jackson 2002a). Although we are confident that soil water and soil temperature were measured in the region characterized by the greatest root and microbial activity, it is possible that there could be relatively high activity (respiration) at deeper depths. If this is the case, then the negative or insignificant temperature sensitivities could be an artifact of spatial misalignment of the measured soil data and the location of biological activity. However, in desert ecosystems, it is important to measure soil temperature in the surface layers because it is arguably the most dynamic part of the soil. Moreover, the surface soil has the most dynamic temperature fluctuations (relative to deeper soil), and small rain events, which typically occur in deserts (Huxman et al. 2004), infiltrate the surface soil and may stimulate surface soil microbes more than deeper microbes. Thus, it is likely that the low sensitivities we observed may be coupled to small rain events that only wet surface layers where microbes predominantly reside. Additional exploration of the controls on the temperature sensitivity of respiration is discussed below in the context of our third question.

\section{Magnitude of respiration}

Regarding our second research question, our results indicate the magnitude of respiration $(R b)$ at $20^{\circ} \mathrm{C}$ differed across some of the deserts depending upon whether the soil was wet or dry (Fig. 2b), but the differences do not appear to be related to the soil carbon content of each desert (Table 1). Our findings suggest that there may be a general desert response of respiration rates in dry soil, but deserts appear to diverge under wet soil conditions, as this is when other factors that vary across deserts may limit soil respiration. The convergence in respiration rates in dry soil is likely due to the primary limitation of water in these systems, particularly for microbial activity in surface soils. The extremely low respiration rates under dry conditions in the Mojave suggests that this desert is either "on" or "off", where current soil moisture switches the system "on" and activates biological activity (e.g., for plants see Nowak et al. 2004). This response might be linked to low annual precipitation and low productivity in the Mojave (Smith et al. 1997), but it should be noted that relatively lower soil carbon content in the Mojave was not observed (Table 2). Recall that we used surface $(0-15 \mathrm{~cm})$ soil water in this analysis, so the Mojave results could also suggest that roots (Wallace et al. 1980) and microbial biomass (Fierer and Schimel 2003) are primarily confined to the surface layers such that deeper water reserves may have little impact on soil respiration.

Soil moisture effects on the temperature sensitivity and magnitude of respiration

Regarding our third question, we found that soil moisture and antecedent precipitation affected the magnitude $(R b)$ and temperature sensitivity $(E o)$ of soil respiration, with some similarity across deserts (Table 4). We found that any soil condition, either current or antecedent, that results in high soil moisture induces respiration (increases $R b$ ) in all but the Mojave. In the Mojave, which is characterized by low MAP and small precipitation events, only high current soil moisture increased $R b$ (Fig. $2 \mathrm{~b}$ and Table 4). Interestingly, high soil moisture reduces the temperature sensitivity in the Sonoran and Great Basin deserts, but neither index of water availability could explain variation in the temperature sensitivities (Eo or $Q_{10}$ ) in the remaining deserts. We expected high soil moisture to increase, but not decrease, the temperature sensitivity of respiration (Conant et al. 2004), but other confounding factors, such as substrate availability, may play a role. Davidson et al. (2006) suggested that many of the effects of temperature and moisture on respiration are related to substrate availability, often in complex ways, and there are significant knowledge gaps in understanding this relationship. 
Although soil moisture and antecedent effects on the temperature sensitivity of respiration were not statistically significant for most of the deserts, it is important to quantify the range of sensitivities that can occur within the soil moisture and antecedent precipitation space for each desert. We found a spectrum of soil moisture and antecedent precipitation conditions that result in temperature insensitivity or negative temperature sensitivity in each desert (Fig. 3). In general, respiration is insensitive to temperature under high antecedent conditions in all but the polar ecosystems, where temperature insensitivity occurs with low soil water content combined with a large range of antecedent conditions (Fig. 3). The relatively wide range of combinations of current and antecedent moisture that yielded non-significant temperature sensitivities, and hence insensitive, may reflect either the "true" temperature sensitivities of these systems or the lack of data for such combinations. The latter is likely the case for the Chihuahuan, Mojave, and sagebrush steppe under high antecedent conditions because posterior means for the predicted $Q_{10}$ values were relatively high (Fig. 3) and the coefficients of variation were very large (Fig. S2). Clearly, more information is required under different combinations of current and antecedent soil moisture to evaluate their effects on the temperature sensitivity of soil respiration.

The polar ecosystems showed positive temperature sensitivity under a wide range of soil moisture conditions (Fig. 3), similar to those observed by Czimczik and Welker (2010) from the same region over the course of the summer, ranging from the lowest rates in the spring to the highest rates in midsummer when air and soil temperatures reach their maximum. Soil and plant processes in polar desert and semi-desert ecosystems are often controlled by soil moisture and or temperature (Welker et al. 1993, 2003, 2004; Robinson et al. 1995), and typically these ecosystems are well-drained with relatively low soil water holding capacity (Horwath et al. 2008). For example, unsaturated conditions result in greater temperature sensitivity of respiration compared to saturated conditions (Davidson et al. 1998). The negative temperature sensitivity in the Great Basin and the lack of sensitivity in the Sonoran are surprising because a positive relationship between respiration and temperature is more commonly reported (Lloyd and Taylor 1994). The Sonoran data were collected during the growing season, so the lack of sensitivity represents the respiration response when the ecosystem is most active. This has important implications for understanding and predicting carbon dynamics in this type of system. Additionally, according to Davidson et al. (2006), there may be confounding effects of substrate supply on the response of respiration to temperature and moisture.

Similarity in desert responses

The deserts' responses grouped together based on climatic indices, which is somewhat expected given that we used the climatic indices to describe potential correlations between deserts. However, the groupings primarily reflect similarities in MAP, with MAT having little impact. In desert ecosystems characterized by "moderate" precipitation inputs such as the Chihuahuan and sagebrush steppe (MAP $=23-$ $36 \mathrm{~cm}$ ), high antecedent precipitation or high current soil moisture positively affected the magnitude of respiration (Table 4). In higher precipitation systems such as the Sonoran and Great Basin (MAP $=56-$ $58 \mathrm{~cm}$ ), high current soil moisture reduced the temperature sensitivity and high antecedent precipitation enhanced the magnitude of respiration (Table 4). In low precipitation systems such as the polar ecosystems and the Mojave (MAP $=7-$ $13 \mathrm{~cm}$ ), antecedent precipitation did not affect the magnitude or sensitivity of respiration (Table 4). Others have found that polar semi-desert soil respiration responds to water additions (Illeris et al. 2003), so it is unclear why we did not observe a response, but it is possible that the water effects observed by others could actually reflect confounding seasonal (date) and temperature effects. We expect, however, that factors such as aboveground productivity, plant phenology, soil nitrogen (Rustad et al. 2001), proximity to plant canopies, or temperature acclimation (Bradford et al. 2008) need to be explored to help explain additional variation in soil respiration in these extreme ecosystems.

Effects of antecedent conditions on respiration

The mechanisms underlying the differential effects of antecedent conditions on $R b$ and $E o$ (and $Q_{10}$ ), and the divergence of $R b$ in wet soils across deserts are unclear. We expect, however, that the depth- 
distribution of soil organisms and the timing and magnitude of precipitation events partly explain the responses to antecedent conditions. Experimental studies show that water additions to dry soil (e.g., low antecedent conditions) elicit rapid and very high respiration rates from soil microbes (Fierer and Schimel 2003; Jarvis et al. 2007). Conversely, high respiration rates in roots develop after longer periods of sustained high soil moisture availability (e.g., high antecedent conditions) (Palta and Nobel 1989; Tang and Baldocchi 2005). Roots and microbes likely have inherent differences in their capacities to grow and up-regulate metabolic processes in response to increased soil moisture at different time scales, and differences in the depth-distribution of roots and microbes may play a role due to variation in the depth of moisture infiltration after precipitation events. For example, microbial density tends to be higher near the soil surface (Cable et al. 2009), while roots tend to growth to greater depth (Schwinning and Ehleringer 2001; Schenk and Jackson 2002a, b). Thus, deep soil moisture may stimulate relatively more root respiration and shallow moisture may stimulate relatively more microbial respiration (Cable and Huxman 2004). Further, the presence of relatively stable, deep soil moisture is expected to be correlated with high antecedent conditions. Thus, soil respiration may be more coupled to antecedent conditions in systems dominated by deep roots and characterized by large precipitation pulses that recharge deep layers. Additionally, the divergence in respiration rates we observed across deserts under wet soil may be related to differences in the microbial and root activity occurring below the depths at which soil moisture was measured. Differences in the relative distribution and activity of roots and microbes at different soil depths across deserts are not well known, and more comprehensive data would lend insight into differential temperature and antecedent responses across deserts.

\section{Broader scale implications and conclusions}

Our study has implications for a broader-scale understanding of the carbon cycle. Currently, models predict that climate change will result in the terrestrial surface acting as a source of $\mathrm{CO}_{2}$ to the atmosphere because soil respiration is expected to be stimulated by warming (Cramer et al. 2001). Further, shifts in patterns of precipitation associated with climate change may interact with warming trends to affect future soil carbon balance. In contrast, we show that temperature can exert both stimulatory and inhibitory effects on soil respiration in deserts, and understanding the complex interactions with soil moisture and antecedent conditions is paramount to predicting the response of deserts and potentially other ecosystem types to climate change. In particular, this study shows that antecedent water conditions warrant further exploration and should be incorporated into carbon cycling models, especially for pulse-driven ecosystems. Antecedent conditions are likely important in other ecosystems such as seasonally dry tropical forests, Mediterranean shrublands, temperate and subtropical grasslands, and semiarid woodlands. Finally, the practice of using simple indices such as a constant $Q_{10}$ of respiration to describe the temperature response of soil respiration is likely to fail when confronted with predicting respiration under highly variable environmental and climatic conditions. We evaluated the $Q_{10}$ of soil respiration in this study and found that it can vary greatly across and within deserts in response to variable soil temperatures, soil water content, and antecedent precipitation. Thus, we concur with Qi et al. (2002) that the temperature sensitivity of respiration needs to be incorporated into ecosystem models as a dynamic rather than a static relationship (e.g., variable $Q_{10}$ ), and moisture conditions at different time scales can control this dynamic behavior.

This study contributes a number of unique findings about desert soil respiration. We show that certain soil moisture conditions can lead to negative temperature sensitivities or insensitivities in many of the deserts studied here. This study suggests that deserts can function very differently from each other-and from more commonly studied mesic ecosystemsunder certain environmental conditions, particularly those related to antecedent conditions. Although the polar ecosystems are viewed as deserts when considering their low MAP, they behave very differently from the warmer deserts with respect to the lack of current or antecedent moisture effects on respiration. This study also identified three key mechanisms that warrant further examination to explain conditions that lead to the uncoupling of soil respiration and temperature in deserts, such as mechanisms that underlie the effects of antecedent conditions on soil 
carbon processes, the temperature response of the different belowground components, and the relative abundance and distribution of belowground components across deserts. Our results have significant implications for large-scale modeling efforts because we highlight the importance of antecedent conditions for desert soil carbon fluxes, and soil respiration responses in mesic ecosystems do not represent the responses in deserts and perhaps other dryland ecosystems.

Acknowledgements We thank Jay Arnone for some temperature data for the Mojave. This synthesis work was supported by a DOE National Institute for Climate Change Research (NICCR) grant to K.O., T.H., M.L., S.S., and D.T. and by the National Science Foundation (NSF) under grant \#EPS0447681. The Mojave Desert study (T.C., R.N., and S.S.) was supported by DOE (DE-FG02-03ER63650, DE-FG0203ER63651), NSF (DEB-0212812), Nevada Agricultural Experiment Station, and DOE National Nuclear Security Administration/Nevada Project Office. The M. Theo Kearney Foundation for Soil Science provided support to M.L. The Chihuahuan study (D.T.) in Big Bend National Park was supported by a U.S. National Park Service grant. The Wyoming sagebrush steppe project (E.P., B.E.E.) was supported by the National Research Initiative of the USDA Cooperative State Research, Education and Extension Service, grant number \#2003-35101-13652, a Wyoming NASA Space Grant Graduate Student Fellowship (M.C.), and the Wyoming Agricultural Experiment Station. The Greenland research was supported by NSF Office of Polar Programs and NSF Biocomplexity \#0221606 (J.M.W.).

Open Access This article is distributed under the terms of the Creative Commons Attribution Noncommercial License which permits any noncommercial use, distribution, and reproduction in any medium, provided the original author(s) and source are credited.

\section{References}

Boone RD, Nadelhoffer KJ, Canary JD et al (1998) Roots exert a strong influence on the temperature sensitivity of soil respiration. Nature 396:570-572

Bradford MA, Davies CA, Frey SD et al (2008) Thermal adaptation of soil microbial respiration to elevated temperature. Ecol Lett 11:1316-1327

Brooks SP, Gelman A (1998) General methods for monitoring convergence of iterative simulations. J Comput Graph Stat 7:434-455

Cable JM, Huxman TE (2004) Precipitation pulse size effects on Sonoran Desert soil microbial crusts. Oecologia 141:317-324

Cable JM, Ogle K, Williams DG et al (2008) Soil texture drives responses of soil respiration to precipitation pulses in the Sonoran Desert: implications for climate change. Ecosystems 11:961-979

Cable JM, Ogle K, Tyler AP et al (2009) Woody plant encroachment impacts on soil carbon and microbial processes: results from a hierarchical Bayesian analysis of soil incubation data. Plant Soil 320:153-167

Cardon ZG, Hungate BA, Cambardella CA et al (2001) Contrasting effects of elevated $\mathrm{CO}_{2}$ on old and new soil carbon pools. Soil Biol Biochem 33:365-373

Chen H, Tian HQ (2005) Does a general temperature-dependent $\mathrm{Q}_{10}$ model of soil respiration exist at biome and global scale? J Integr Plant Biol 47:1288-1302

Christensen JH, Hewitson B, Busuioc A et al (2007) Regional climate projections. In: Solomon S, Quin D, Manning M, Chen Z, Marquis M, Averyt KB, Tignor M, Miller HL (eds) Climate change 2007: the physical science basis. Contribution of working group I to the fourth assessment report of the intergovernmental panel on climate change. Cambridge University Press, Cambridge, UK/New York, NY, USA

Clark JS (2005) Why environmental scientists are becoming Bayesians. Ecol Lett 8:2-14

Cleary MB, Pendall E, Ewers BE (2008) Testing sagebrush allometric relationships across three fire chronosequences in Wyoming, USA. J Arid Environ 72:285-301

Conant RT, Dalla-Betta P, Klopatek CC et al (2004) Controls on soil respiration in semiarid soils. Soil Biol Biochem 36:945-951

Connin SL, Virginia RA, Chamberlain CP (1997) Carbon isotopes reveal soil organic matter dynamics following arid land shrub expansion. Oecologia 110:374-386

Cramer W, Bondeau A, Woodward FI et al (2001) Global response of terrestrial ecosystem structure and function to $\mathrm{CO}_{2}$ and climate change: results from six dynamic global vegetation models. Glob Change Biol 7:357-373

Czimczik C, Welker JM (2010) Radiocarbon $\left({ }^{14} \mathrm{C}\right)$ content of $\mathrm{CO}_{2}$ respired from High Arctic tundra in NW Greenland. Arctic Antarct Alpine Res, in press

Davidson EA, Belk E, Boone RD (1998) Soil water content and temperature as independent or confounded factors controlling soil respiration in a temperate mixed hardwood forest. Glob Change Biol 4:217-227

Davidson EA, Janssens IA, Luo YQ (2006) On the variability of respiration in terrestrial ecosystems: moving beyond $\mathrm{Q}_{10}$. Glob Change Biol 12:154-164

Diggle PJ, Heagerty P, Liange K-Y et al (2002) Analysis of longitudinal data. Oxford University Press, New York

Dregne HE (1983) Desertification of Arid Lands. Harwood Academic, New York

English NB, Weltzin JF, Fravolini A et al (2005) The influence of soil texture and vegetation on soil moisture under rainout shelters in a semi-desert grassland. J Arid Environ 63:324-343

Ewers BE, Pendall E (2008) Spatial patterns in leaf area and plant functional type cover across chronosequences of sagebrush ecosystems. Plant Ecol 194:67-83

Fierer N, Schimel JP (2002) Effects of drying-rewetting frequency on soil carbon and nitrogen transformations. Soil Biol Biochem 34:777-787

Fierer N, Schimel JP (2003) A proposed mechanism for the pulse in carbon dioxide production commonly observed 
following the rapid rewetting of a dry soil. Soil Sci Soc Am J 67:798-805

Fierer N, Allen AS, Schimel JP et al (2003) Controls on microbial $\mathrm{CO}_{2}$ production: a comparison of surface and subsurface soil horizons. Glob Change Biol 9:13221332

Fierer N, Colman BP, Schimel JP et al (2006) Predicting the temperature dependence of microbial respiration in soil: a continental-scale analysis. Global Biogeochem Cycles 20:GB3026

Geist HJ, Lambin EF (2004) Dynamic causal patterns of desertification. Bioscience 54:817-829

Gelman A (2004) Parameterization and Bayesian modeling. J Am Stat Assoc 99:537-545

Gelman A (2006) Prior distributions for variance parameters in hierarchical models. Bayesian Anal 1:515-533

Gershenson A, Bader NE, Cheng WX (2009) Effects of substrate availability on the temperature sensitivity of soil organic matter decomposition. Glob Change Biol 15:176183

Gilks WR, Roberts GO (1996) Strategies for improving MCMC. In: Gilks WR, Richardson S, Spiegelhalter DJ (eds) Markov Chain Monte Carlo in practice: interdisciplinary statistics. Chapman \& Hall/CRC, Boca Raton, p 486

Hibbard KA, Schimel DS, Archer S et al (2003) Grassland to woodland transitions: integrating changes in landscape structure and biogeochemistry. Ecol Appl 13:911-926

Horwath JL, Sletten RS, Hagedorn B et al (2008) Spatial and temporal distribution of soil organic carbon in nonsorted striped patterned ground of the High Arctic. J Geophys Res-Biogeosci 113:G03S07

Huxman TE, Cable JM, Ignace DD et al (2004) Response of net ecosystem gas exchange to a simulated precipitation pulse in a semi-arid grassland: the role of native versus non-native grasses and soil texture. Oecologia 141:295305

Illeris L, Michelsen A, Jonasson S (2003) Soil plus root respiration and microbial biomass following water, nitrogen, and phosphorus application at a high arctic semi desert. Biogeochemistry 65:15-29

Jackson RB, Canadell J, Ehleringer JR et al (1996) A global analysis of root distributions for terrestrial biomes. Oecologia 108:389-411

Jackson CH, Best NG, Richardson S (2009) Bayesian graphical models for regression on multiple data sets with different variables. Biostatistics 10:335-351

Jarvis P, Rey A, Petsikos C et al (2007) Drying and wetting of Mediterranean soils stimulates decomposition and carbon dioxide emission: the "Birch effect". Tree Physiol 27:929-940

Jin Z, Dong YS, Qi YC et al (2009) Precipitation pulses and soil $\mathrm{CO}_{2}$ emission in desert shrubland of Artemisia ordosica on the Ordos Plateau of Inner Mongolia, China. Pedosphere 19:799-807

Jordan DN, Zitzer SF, Hendrey GR et al (1999) Biotic, abiotic and performance aspects of the Nevada Desert Free-Air $\mathrm{CO}_{2}$ Enrichment (FACE) Facility. Glob Change Biol 5:659-668

Lloyd J, Taylor JA (1994) On the temperature-dependence of soil respiration. Funct Ecol 8:315-323
Loik ME, Breshears DD, Lauenroth WK et al (2004) A multiscale perspective of water pulses in dryland ecosystems: climatology and ecohydrology of the western USA. Oecologia 141:269-281

Loik ME, Alpert H, Griffith AB (2009) Climate change and snow depth impacts on vegetation at the Great Basin Desert-Sierra Nevada ecotone. In: French A (ed) Climate change and biodiversity in the Americas. Smithsonian Institution Scholarly Press

McCulley RL, Archer SR, Boutton TW et al (2004) Soil respiration and nutrient cycling in wooded communities developing in grassland. Ecology 85:2804-2817

Nowak RS, Zitzer SE, Babcock D et al (2004) Elevated atmospheric $\mathrm{CO}_{2}$ does not conserve soil water in the Mojave Desert. Ecology 85:93-99

Noy-Meir I (1973) Desert ecosystems: environment and producers. Annu Rev Ecol Syst 4:25-51

Ogle K, Barber JJ (2008) Bayesian data-model integration in plant physiological and ecosystem ecology. Prog Bot 69:281-311

Palta JA, Nobel PS (1989) Influences of water status, temperature, and root age on daily patterns of root respiration for 2 cactus species. Ann Bot-Lond 63:651-662

Parton WJ, Scurlock JMO, Ojima DS et al (1993) Observations and modeling of biomass and soil organic-matter dynamics for the grassland biome worldwide. Global Biogeochem Cycles 7:785-809

Patrick L, Cable J, Potts D et al (2007) Effects of an increase in summer precipitation on leaf, soil, and ecosystem fluxes of $\mathrm{CO}_{2}$ and $\mathrm{H}_{2} \mathrm{O}$ in a sotol grassland in Big Bend National Park, Texas. Oecologia 151:704-718

Peng S, Piao S, Wang T et al (2009) Temperature sensitivity of soil respiration in different ecosystems in China. Soil Biol Biochem 41:1008-1014

Pregitzer KS, Laskowski MJ, Burton AJ et al (1998) Variation in sugar maple root respiration with root diameter and soil depth. Tree Physiol 18:665-670

Pumpanen J, Kolari P, Ilvesniemi H et al (2004) Comparison of different chamber techniques for measuring soil $\mathrm{CO}_{2}$ efflux. Agric For Meteorol 123:159-176

Qi Y, Xu M, Wu JG (2002) Temperature sensitivity of soil respiration and its effects on ecosystem carbon budget: nonlinearity begets surprises. Ecol Model 153:131-142

Raich JW, Potter CS (1995) Global patterns of carbon-dioxide emissions from soils. Global Biogeochem Cycles 9:23-36

Reynolds JF (2001) Desertification. In: Levin S (ed) Encyclopedia of biodiversity. Academic Press, San Diego, pp $61-78$

Robinson CH, Wookey PA, Parsons AN et al (1995) Responses of plant litter decomposition and nitrogen mineralization to simulated environmental change in a high arctic polar semi-desert and a subarctic dwarf shrub heath. Oikos 74:503-512

Rogers M, Sullivan PF, Welker JM (2010) Evidence of an optimal snow depth for growing season net $\mathrm{CO}_{2}$ uptake in a Greenlandic high arctic ecosystem. Arctic Antarct Alpine Res, in press

Rustad LE, Campbell JL, Marion GM et al (2001) A metaanalysis of the response of soil respiration, net nitrogen mineralization, and aboveground plant growth to experimental ecosystem warming. Oecologia 126:543-562 
Schaeffer SM, Billings SA, Evans RD (2003) Responses of soil nitrogen dynamics in a Mojave Desert ecosystem to manipulations in soil carbon and nitrogen availability. Oecologia 134:547-553

Schenk HJ, Jackson RB (2002a) The global biogeography of roots. Ecol Monogr 72:311-328

Schenk HJ, Jackson RB (2002b) Rooting depths, lateral root spreads and below-ground/above-ground allometries of plants in water-limited ecosystems. J Ecol 90:480-494

Schimel DS, Braswell BH, Holland EA et al (1994) Climatic, edaphic, and biotic controls over storage and turnover of carbon in soils. Global Biogeochem Cycles 8:279-293

Schlesinger WH, Raikes JA, Hartley AE et al (1996) On the spatial pattern of soil nutrients in desert ecosystems. Ecology 77:364-374

Schwinning S, Ehleringer JR (2001) Water use trade-offs and optimal adaptations to pulse-driven arid ecosystems. J Ecol 89:464-480

Seager R, Ting MF, Held I et al (2007) Model projections of an imminent transition to a more arid climate in southwestern North America. Science 316:1181-1184

Simunek J, Nimmo JR (2005) Estimating soil hydraulic parameters from transient flow experiments in a centrifuge using parameter optimization technique. Water Resour Res 41. doi:10.1029/2004WR003379

Smith SD, Monson R, Anderson JE (1997) Physiological ecology of North American desert plants. Springer, p 286

Spiegelhalter DJ, Best NG, Carlin BR et al (2002) Bayesian measures of model complexity and fit. J R Stat Soc B 64:583-616

Sponseller RA (2007) Precipitation pulses and soil $\mathrm{CO}_{2}$ flux in a Sonoran Desert ecosystem. Glob Change Biol 13: 426-436
Sullivan PF, Welker JM, Steltzer H et al (2008) Energy and water additions give rise to simple responses in plant canopy and soil microclimates of a high arctic ecosystem. J Geophys Res Biogeosci 113:G03S08. doi:10.1029/2007J G000477

Tang JW, Baldocchi DD (2005) Spatial-temporal variation in soil respiration in an oak-grass savanna ecosystem in California and its partitioning into autotrophic and heterotrophic components. Biogeochemistry 73:183-207

Wallace A, Romney EM, Cha JW (1980) Depth distribution of roots of some perennial plants in the Nevada test site area of the northern Mojave Desert, Nevada, USA. Great Basin Nat Mem 4:201-207

Welker JM, Wookey PA, Parsons AN et al (1993) Leaf carbonIsotope discrimination and demographic responses of Dryas octopetala to temperature and water manipulations in a high arctic polar semidesert, Svalbard. Oecologia 95:463-469

Welker JM, Jonsdottir IS, Fahnestock JT (2003) Leaf isotopic (delta C-13 and delta N-15) and nitrogen contents of Carex plants along the Eurasian Coastal Arctic: results from the Northeast Passage expedition. Polar Biol 27:29-37

Welker JM, Fahnestock JT, Henry GHR et al (2004) $\mathrm{CO}_{2}$ exchange in three Canadian High Arctic ecosystems: response to long-term experimental warming. Glob Change Biol 10:1981-1995

Weltzin JF, Loik ME, Schwinning S et al (2003) Assessing the response of terrestrial ecosystems to potential changes in precipitation. Bioscience 53:941-952

Xu LK, Baldocchi DD, Tang JW (2004) How soil moisture, rain pulses, and growth alter the response of ecosystem respiration to temperature. Global Biogeochem Cycles 18: GB4002 